\title{
SSL Protocol Analysis Based on Freshness Identifiers
}

\author{
Yu LIU ${ }^{1, a}$, YanmeiKANG $^{1, \mathrm{~b},{ }^{*}, \text { WenyongLI }}{ }^{1}$ \\ ${ }^{1}$ School of Information Science and Technology, University of International Relations, China

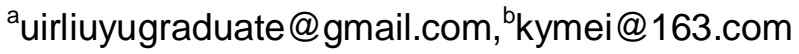 \\ ${ }^{*}$ Corresponding author
}

Keywords : freshness identifier, network security protocol, SSL, MITM

\begin{abstract}
SSL protocol is essential in network security. This paper evaluates the security of SSL protocol by a fine-grained analysis method based on freshness identifiers and proposes the causes of two kinds of MITM attacks under the circumstance of admitting the difficulties of building a trusted session key without a PKI or a long-term hold shared key. These evaluation and analysis have certain reference significance on protocols analysis.
\end{abstract}

\section{Introduction}

As we all know, network security is an important part in our daily life and SSL protocol is essential in network security, therefore it is essential to evaluate the security of SSL protocol. This paper proposes a method of protocol analysis which is a fine-grained analysis of communication steps based on freshness identifiers.

The traditional classification and system models of security protocols [1-2]could be divided into three different methods: the structural reasoning models like BAN logic [3],the structural attacking models like Dolev-Yao model [4] and the structural proving models. The structural proving models, also known as the structural analysis based on proof, which gives a clear distinction of the body's credibility, use the powerful technology of invariant and the axiom of attackers, to pursuit an automatic process. Paulson Induction [5], Schneider Rank Function and Strand Space [6] are three significant methods in the structural analysis of proof.

Based on the Strand Space, Dong Ling proposed a belief multisets formalism for analyzing cryptographic protocols [7] in 2009 which is based on freshness principle, the method is simple and effective in the analysis of security protocols. And in 2010 Chen Zheng-Jie proposed Security Analysis of Cryptographic Protocols Based on Fine-Grained Freshness [8] as a further complements. Definitions of freshness, secrecy and signed messages, have been gradually specified with exact equations [7-8]. The security of cryptographic protocols depends on its trusted freshness identifiers or one-way conversions of the freshness identifiers sent or received during the communication. In 2012 another formalism analysis method based on freshness identifier has been proposed, which describes relevant knowledge and processes in a more concrete way [9].

This paper evaluates the security of SSL protocol in a fine-grained analysis of communication steps by a new method, and proposes the causes of two kinds of MITM attacks under the circumstance of 
admitting the difficulties of building a trusted session key without a PKI or a long-holing shared key, and gives some relevant suggestions eventually.

\section{Network security protocols analysis based on freshness identifier}

In order to use the freshness identifier to analysis any protocol, it is necessary to clear define the used equations and theorems. Here are some basic definitions and the main steps of freshness analysis.

Definition1: (Freshness Identifier) Also known as time variable parameter (TVP), which is used only once under the same purpose, includes random number, serial number and time stamp.

Definition2: (Freshness) During the running period of protocol $\Pi$, freshness identifier $N$ has not been used before time $\mathrm{t} 0$ and it is specially generated for this protocol.

Definition3:(Trusted Freshness) Giving a protocol $\Pi$ between participants A and B, assuming the existence of an arbitrary polynomial time probabilistic attacker I, the attacker takes complete control of the communications link (Dolev-Yao Model [4]), then the freshness identifier $\gamma$ is fresh or $\gamma$ is a trusted freshness identifier to participant A if $\gamma$ satisfies one of the following conditions:

1) Freshness identifier $\gamma$ is generated by the participants A itself.

2) Freshness identifier $\gamma$ is a time stamp, and the timestamp differences between sender and receiver are in an acceptable range.

3) A has conclusive proof that $\gamma$ is fresh. The conclusive evidence can be a signature, a MAC, or other one-way conversion includes the freshness identifier $\gamma$.

The main analysis processes of a protocol are as following:

1) To specify the security goals of each communication step for a certain protocol

2) To specify the initialstate of this protocol and its all used basic assumptions

3) To specify the securityattributions based on the theorem of freshness and its inference, when sending and receiving a generalized monoidal transform which contains an identifier of freshness observed from the operative subject

4) To compare these attributions with each security goal

\section{The Analysis on the Freshness of SSL Protocol}

As we known, SSL protocol is an essential protocol widely used in the communication on the Internet, and the analysis of freshness is an effective method to detect the security of protocols. Therefore, it is necessary to evaluate the security of SSL protocol by freshness analysis.

The steps of communication in SSL protocol are as following:

1) $\mathrm{C} \rightarrow \mathrm{S}: \mathrm{Ver}_{\mathrm{C}}, \mathrm{T}_{\mathrm{C}}, \mathrm{N}_{\mathrm{C}}, \mathrm{NULL}^{1}$

2) $\mathrm{S} \rightarrow \mathrm{C}: \operatorname{Ver}_{\mathrm{S}}, \mathrm{T}_{\mathrm{S}}, \mathrm{N}_{\mathrm{S}}, \mathrm{SID}_{\mathrm{S}}, \mathrm{Cert}_{\mathrm{S}}$

3) $\mathrm{C} \rightarrow \mathrm{S}:\left\{\mathrm{k}_{\mathrm{CS}}\right\}_{\mathrm{K}_{\mathrm{S}}}, \operatorname{Cert}_{\mathrm{C}},\left\{\mathrm{N}_{\mathrm{C}}, \mathrm{N}_{\mathrm{S}}\right\}_{\mathrm{K}_{\mathrm{C}}^{-1}},\left\{\mathrm{C},\left\{\mathrm{N}_{\mathrm{C}}, \mathrm{N}_{\mathrm{S}}\right\}_{\mathrm{K}_{\mathrm{C}}^{-1}}\right\}_{\mathrm{k}_{\mathrm{CS}}}$

4) $\mathrm{S} \rightarrow \mathrm{C}:\left\{\mathrm{S}, \mathrm{N}_{\mathrm{C}}, \mathrm{N}_{\mathrm{S}}\right\}_{\mathrm{k}_{\mathrm{CS}}}$

We could analyze the freshness of SSL protocol by these four proceeding processes.

Therefore, based on the design of SSL protocol and the acceptance the correctness of public key and the confidentiality of private key, the primary credible sets can be represented like this:

${ }^{1} \mathrm{C}=\mathrm{Client}, \mathrm{S}=$ Server, Ver=Verifications, $\mathrm{T}=$ Timestamp, $\mathrm{N}=$ Radom number, Sid=Signature, Cert=Certification 


$$
\begin{aligned}
& \operatorname{bel}(C)=\{\operatorname{secret}(C)=\{\operatorname{priv}(K C)\}, \operatorname{secret}(S)=\{\operatorname{priv}(K S)\}\} \\
& \operatorname{bel}(S)=\{\operatorname{secret}(S)=\{\operatorname{priv}(K S)\}, \operatorname{secret}(C)=\{\operatorname{priv}(K C)\}\}
\end{aligned}
$$

For the first message $M_{1}=C \rightarrow S: \operatorname{Ver}_{C}, T_{C}, N_{C}, N U L$, after $C$ has sent message $M_{1}$ to $S$, according to the theorem of freshness ${ }^{2}[9], C$ believes the identifiers $T_{C}, N_{C}$ possess the attribution of freshness since both identifiers are produced by himself. However, $C$ and $S$ consider the tokens $T_{C}, N_{C}$ do not have the confidentiality since the information is transmitted in plaintext. After $S$ has received the message $\mathrm{M}_{1}$, he believes there is no credibility since the uncertainty of the source. The attributions of first message could be represented as following:

$$
\begin{aligned}
\operatorname{bel}(C)= & \left\{\operatorname{fresh}(C)=\left\{T_{C}, N_{C}\right\}\right\} \\
& \operatorname{bel}(S)=\{\varnothing\}
\end{aligned}
$$

For the second message $\mathrm{M}_{2}=\mathrm{S} \rightarrow \mathrm{C}: \mathrm{Ver}_{\mathrm{S}}, \mathrm{T}_{\mathrm{S}}, \mathrm{N}_{\mathrm{S}}, \mathrm{SID}_{\mathrm{S}}$, Cert $\mathrm{S}_{\mathrm{S}}$, after $\mathrm{S}$ has sent message $\mathrm{M}_{2}$ to $\mathrm{C}$, according to the theorem of freshness, $S$ believes the identifiers $T_{S}, N_{S}$ possess the attribution of freshness since both identifiers are produced by himself.However, $\mathrm{C}$ and $\mathrm{S}$ consider the tokens $\mathrm{T}_{S}, \mathrm{~N}_{S}$ do not have the confidentiality since the information are transmitted in plaintext. After $\mathrm{C}$ has received the message $\mathrm{M}_{2}$, he believes there is no credibility since the uncertainty of the source. The attributions of second message could be represented as following:

$$
\begin{aligned}
\operatorname{bel}(S) & =\left\{\operatorname{fresh}(S)=\left\{T_{S}, N_{S}\right\}\right\} \\
\operatorname{bel}(C) & =\left\{\operatorname{fresh}(C)=\left\{T_{C}, N_{C}\right\}\right\}
\end{aligned}
$$

For the third message $\mathrm{M}_{3}=\mathrm{C} \rightarrow \mathrm{S}$ : $\left\{\mathrm{k}_{\mathrm{CS}}\right\}_{\mathrm{K}_{\mathrm{S}}}, \mathrm{Cert}_{\mathrm{C}},\left\{\mathrm{N}_{\mathrm{C}}, \mathrm{N}_{\mathrm{S}}\right\}_{\mathrm{K}_{\mathrm{C}}^{-1}},\left\{\mathrm{C},\left\{\mathrm{N}_{\mathrm{C}}, \mathrm{N}_{\mathrm{S}}\right\}_{\mathrm{K}_{\mathrm{C}}^{-1}}\right\}_{\mathrm{k}_{\mathrm{CS}}}$, after C has sent message $M_{3}$ to $\mathrm{C}$, according to the theorem of freshness, $\mathrm{C}$ believes the piece $\left\{\mathrm{k}_{\mathrm{CS}}\right\}$ has the credibility and the piece $\left\{\mathrm{C},\left\{\mathrm{N}_{\mathrm{C}}, \mathrm{N}_{\mathrm{S}}\right\}_{\mathrm{K}_{\mathrm{C}}^{-1}}\right\}_{\mathrm{k}_{\mathrm{CS}}}$ possess the attribution of identity of $\mathrm{C}$. Therefore, according to the theorem ${ }^{3}, \mathrm{C}$ believes $M_{3}$ is the signature message of $\mathrm{C}$, then according to the theorem ${ }^{4}, \mathrm{C}$ believes $\mathrm{k}_{\mathrm{CS}}$ is the implicit secret shared only with $\mathrm{C}$ and $\mathrm{S}$. After $\mathrm{S}$ has received the message $M_{3}$, he believes the message $M_{3}$ is created by $\mathrm{C}$ according to the theorem ${ }^{5}$.So the attributions of third message could be represented as following:

$$
\begin{gathered}
\operatorname{bel}(\mathrm{C})=\left\{\operatorname{fresh}(\mathrm{C})=\left\{\mathrm{T}_{\mathrm{C}}, \mathrm{N}_{\mathrm{C}}, \mathrm{k}_{\mathrm{CS}}\right\}, \operatorname{fresh}(\mathrm{S})=\left\{\mathrm{T}_{\mathrm{S}}, \mathrm{N}_{\mathrm{S}}\right\}, \operatorname{onym}(\mathrm{C})=\left\{\mathrm{M}_{3}\right\},\right. \\
\left.\operatorname{des}(\mathrm{S})=\left\{\mathrm{M}_{3}\right\}, \operatorname{impsecret}(\mathrm{C}, \mathrm{S})=\left\{\mathrm{k}_{\mathrm{CS}}\right\}\right\} \\
\operatorname{bel}(\mathrm{S})=\left\{\operatorname{fresh}(S)=\left\{\mathrm{T}_{\mathrm{S}}, \mathrm{N}_{\mathrm{S}}, \mathrm{k}_{\mathrm{CS}}\right\}, \operatorname{gen}(\mathrm{C})=\left\{\mathrm{M}_{3}\right\}\right\}
\end{gathered}
$$

For the fourth message $\mathrm{M}_{4}=\mathrm{S} \rightarrow \mathrm{C}:\left\{\mathrm{S}, \mathrm{N}_{\mathrm{C}}, \mathrm{N}_{\mathrm{S}}\right\}_{\mathrm{k}_{\mathrm{CS}}}$, after $\mathrm{S}$ sent message $M_{4}$ to $\mathrm{C}$, according to the theorem 1 of message ${ }^{6}, \mathrm{C}$ believes $\mathrm{S}$ has received the message $M_{3}$, and therefore according to the

\footnotetext{
${ }^{2} \frac{\operatorname{gen}(A)=\{N\}}{\operatorname{bel}(A)=\{\operatorname{fresh}(A)=\{N\}\}}$, this and the following theorems are from reference [9].

$\underline{\operatorname{3gen}(A)=\{M\}, A \in I(M), \operatorname{bel}(A)=\{\operatorname{fresh}(A)=\{M\}\}}$

$\operatorname{bel}(\mathrm{A})=\{\operatorname{onym}(\mathrm{A})=\{\mathrm{M}\}\}$

$4 \operatorname{gen}(A)=\{M\}, N \notin I(M), \operatorname{bel}(A)=\{\operatorname{onym}(A)=\{M\}, \operatorname{des}(B)=\{M\}, \operatorname{fresh}(A)=\{M\}\}$

$\operatorname{bel}(A)=\{\operatorname{impsecret}(A, B)=\{N\}\}$

${ }_{5} \operatorname{rec}(A)=\{m M\}, \operatorname{priv}(K)=\operatorname{key}(m M), \operatorname{bel}(A)=\{\operatorname{secret}(B)=\{\operatorname{priv}(K)\}, \operatorname{fresh}(A B)=\{m M\}\}$

$\operatorname{bel}(A)=\{\operatorname{gen}(B)=\{m M\}\}$

${ }_{6} \operatorname{rec}(A)=\{N\}, N \notin I(M), \operatorname{gen}(A)=\{M\}, \operatorname{bel}(A)=\{\operatorname{des}(B)=\{M\}, \operatorname{fresh}(A)=\{N\}\}$

$\operatorname{bel}(A)=\{\operatorname{rec}(B)=\{M\}\}$
} 
theorem 1 of message ${ }^{7}$ the attributions of fourth message could be represented like this:

$$
\begin{gathered}
\operatorname{bel}(\mathrm{S})=\left\{\operatorname{fresh}(\mathrm{S})=\left\{\mathrm{k}_{\mathrm{CS}}, \mathrm{T}_{\mathrm{S}}, \mathrm{N}_{\mathrm{S}}\right\}\right\} \\
\operatorname{bel}(\mathrm{C})=\left\{\operatorname{fresh}(\mathrm{C})=\left\{\mathrm{T}_{\mathrm{C}}, \mathrm{N}_{\mathrm{C}}, \mathrm{k}_{\mathrm{CS}}, \mathrm{T}_{\mathrm{S}}, \mathrm{N}_{\mathrm{S}}\right\}, \operatorname{rec}(\mathrm{S})=\left\{\mathrm{M}_{3}\right\}\right. \\
\left.\operatorname{fresh}(\mathrm{S})=\left\{\mathrm{k}_{\mathrm{CS}}\right\}, \operatorname{secret}(\mathrm{C}, \mathrm{S})=\left\{\mathrm{k}_{\mathrm{CS}}\right\}\right\}
\end{gathered}
$$

Overall the identifiers of freshness related with session key could be represented as following:

$$
\begin{gathered}
\operatorname{bel}(\mathrm{S})=\left\{\operatorname{fresh}(\mathrm{S})=\left\{\mathrm{k}_{\mathrm{CS}}\right\}\right\} \\
\operatorname{bel}(\mathrm{C})=\left\{\operatorname{fresh}(\mathrm{C})=\left\{\mathrm{k}_{\mathrm{CS}}\right\}, \operatorname{fresh}(\mathrm{S})=\left\{\mathrm{k}_{\mathrm{CS}}\right\}, \operatorname{secret}(\mathrm{C}, \mathrm{S})=\left\{\mathrm{k}_{\mathrm{CS}}\right\}\right\}
\end{gathered}
$$

Comparing these attributions with the primary security goal could be showed as following:

$$
\begin{aligned}
& \operatorname{bel}(\mathrm{S})=\left\{\operatorname{fresh}(\mathrm{S})=\left\{\mathrm{k}_{\mathrm{CS}}\right\}, \text { fresh }(\mathrm{C})=\left\{\mathrm{k}_{\mathrm{CS}}\right\}, \operatorname{secret}(\mathrm{C}, \mathrm{S})=\left\{\mathrm{k}_{\mathrm{CS}}\right\}\right\} \\
& \operatorname{bel}(\mathrm{C})=\left\{\operatorname{fresh}(\mathrm{C})=\left\{\mathrm{k}_{\mathrm{CS}}\right\}, \text { fresh }(\mathrm{S})=\left\{\mathrm{k}_{\mathrm{CS}}\right\}, \operatorname{secret}(\mathrm{C}, \mathrm{S})=\left\{\mathrm{k}_{\mathrm{CS}}\right\}\right\}
\end{aligned}
$$

It is easy to find out SSL protocol's defect that $\mathrm{S}$ fails to build the recognition thatk $\mathrm{CS}_{\text {possesses the }}$ freshness with credibility and $\mathrm{k}_{\mathrm{CS}}$ is the shared session key. This defect has been exploited by the attacks showed as figure 1:

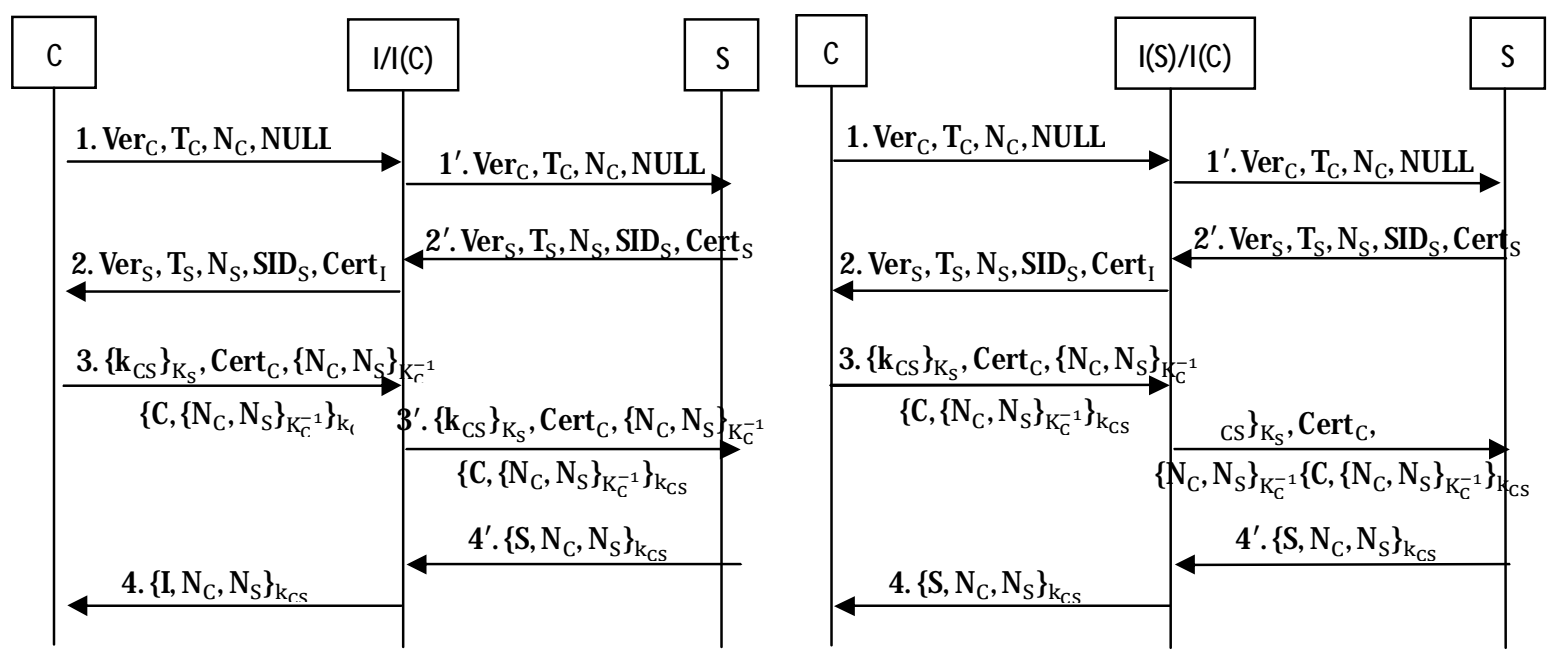

Fig. 1 Single-way and double-way MITM attacks

Besides, the danger of being deceiving is attributed only to $\mathrm{S}$, not including $\mathrm{C}$, rather than both sides which was proposed by the reference [9]. The main cause of this danger comes from the uncertainty of the source of the message which $\mathrm{S}$ has received and where the corresponding response was to arrive. Meanwhile, all the attribution sets of $\mathrm{C}$ contain the essential freshness with credibility, which ensures the security of $\mathrm{C}$ himself according the analysis of freshness.

Therefore, though Lin Xian-Jin have proposed one solution [10], it fails to reach the original purpose of the SSL protocol, which means to build one trusted session key under the circumstance of lacking a PKI. Whereas, now no authority has proposed a satisfied method that could build a trusted session key when no one knows each's public key and no trust CA exists. Nowadays, a common solution is to enhance the management of Web security, including PC protecting such as ARP spoofing Prevention, DNS spoofing prevention, malicious hijack protection, redirect software[11-12] and SSL protocols application in a more secure way like SSL mutual authentication[13].

${ }_{7} \mathrm{~N} \in \mathrm{I}(\mathrm{M}), \operatorname{bel}(\mathrm{A})=\{\operatorname{rec}(\mathrm{B})=\{\mathrm{M}\}\}$

$\operatorname{bel}(A)=\{\operatorname{rec}(B)=\{N\}\}$ 


\section{Conclusions}

This paper presents a fresh and fine-grained analysis method of network security protocols and applies this analysis method in SSL protocol analysis, and presents that only $\mathrm{S}$ is deceived and does not contain $\mathrm{C}$ under MITM attacks. This paper also proposes that building a trusted session key is a difficult proposition between the two sides without long-term shared secret keys and both public keys. It is a difficult proposition that building a trusted session key without one shared secret key or trusted public-keys. These analyses may have some certain reference significance on the field of network security.

\section{Acknowledgements}

This paper is supported by the Fundamental Research Funds for the Central Universities under Grant NO.3262015T81.

\section{References}

[1] FENG Deng-Guo, Fan Hong. Survey on Theories and Methods of Formal Analyses for Security Protocols[J].Journal of the Graduate School of the Chinese Academy of Sciences. 2003, Vol20, No.4:389-404

[2] P F Syverson, P C van Oorschot. On Unified Some Cryptographic Protocol Logics .In: Proceedings of the 1994 .IEEE Computer Society Press , 1994

[3] WANG Zheng-cai, XU Dao-yun. Reliability Analysis and Improvement of BAN Logic. Computer Engineering,Vol.38 No.17, September 2012:110 115

[4] TANG Zheng-yi , LI Xiang. The Formalization Description of theDolev-Yao Intruder Model.Computer Engineering \& Science, Vol.32 , No.8, 2010:36 45

[5] L C Paulson .Proving Properties of Security Protocols by Induct ion .Proceedings of the IEEE

Computer Security Foundations Workshop X. IEEE Computer Society Press, $1997.70 \sim 83$

[6] F Javier Thayer Fabrega, Jonathan C Herzog, Joshua D Guttman. Honest Ideals on Strand Spaces .In :Proc $11^{\text {th }}$ IEEE Computer Security Foundations Workshop(CS FW).IEEE Computer Society Press , 1998

[7] Dong Ling, Chen Ke-Fei, Lai Xue-Jia. Belief Multisets Formalism for Analyzing Cryptographic Protocols[J]. Journal of Software, Vol.20, No.11, November 2009, pp.3060-3076

[8] Chen zheng-Jie, Chen Ke-Fei, Lai Xue-Jia. Security Analysis of Cryptographic Protocols Based on Fine-Grained Freshness [J]Acta Scientiarum Naturalium Universitatis Pekinensis. Vol. 46 , No. 5, 2010:763-770

[9] Dong Ling, Chen Ke-Fei. Formalism Analysis Method Based on Freshness Identifier [M]. Beijing: 
Higher Education Press 2012.11

[10] Lin Xian-Jin, Hu Shan-Li. Informal Methods for the Analysis of Authentication Protocols [J]. Mini-micro Systems. Vol. 24 No. 11:1912-1915. Nov. 2003

[11] KANG Rong-Bao,ZHANG Ling,LAN Kun. Analysis and Countermeasure of SSL MITM Attack

[J]. The 30th Institute of China Electronic Technology Company , Chengdu Sichuan 610041.

Information Security and Communications Privacy. 2010.3:85-90

[12]JIA Jing, XUE Zhi. The Principle and Prevention of SSL Man-in-the-middle Attack [J].

Information Security and Communications Privacy. 2007(04) : 108-110

[13] QIAO Yan-fei. The SSL Security Analysis and the Research of Middleman Attack and Prevention[D].Beijing University of Posts and Telecommunications.2013 